\title{
Changes in sleep timing and subjective sleep quality during the COVID-19 lockdown in Italy and Belgium: age, gender and working status as modulating factors
}

\author{
Nicola Cellini ${ }^{1,2,3,4 \dagger}$, Francesca Conte ${ }^{5}$, Oreste De Rosa ${ }^{5}$, Fiorenza Giganti ${ }^{6}$, Serena Malloggi ${ }^{6}$, \\ Mathilde Reyt ${ }^{7,8}$, Camille Guillemin ${ }^{7,8}$, Christina Schmidt ${ }^{7,8}$, Vincenzo Muto ${ }^{7,8, \# \text {, }}$ \\ Gianluca Ficca ${ }^{5, \#}$ \\ 1 Department of General Psychology, University of Padova, Padova, Italy; \\ ${ }_{2}$ Department of Biomedical Sciences, University of Padova, Padova, Italy; \\ ${ }_{3}$ Padova Neuroscience Center, University of Padova, Padova, Italy; \\ ${ }_{4}$ Human Inspired Technology Center, University of Padova, Padova, Italy; \\ 5 Department of Psychology, University of Campania "L. Vanvitelli", Caserta, Italy; \\ ${ }_{6}$ Department of Neuroscience, Psychology, Drug Research and Child Health, University of Firenze, \\ Firenze, \\ Italy; \\ 7 GIGA-Cyclotron Research Centre-In Vivo Imaging, University of Liège, Liège, Belgium; \\ ${ }_{8}$ Psychology and Cognitive Neuroscience Research Unit, University of Liège, Liège, Belgium; \\ \#These authors equally contributed to this work. \\ +Corresponding author: nicola.cellini@unipd.it
}

Declaration of Conflicting Interests: The Authors declare that there is no conflict of interest. Acknowledgment: MR and VM are supported by a European Research Council starting grant (CS; ERC-StG 757763), CS is a research associate at the by the Belgian National Funds for Scientific

Research. The present work was carried out in the scope of the research program

"Dipartimenti di Eccellenza" from MIUR to the Department of General Psychology of the University

of Padova. 


\begin{abstract}
Italy and Belgium have been among the first western countries to face the Coronavirus disease 2019 (COVID-19) emergency, imposing a total lockdown over the entire national territories. These limitations have proven effective in slowing down the spread of the infection. However, the benefits obtained in public health have come with huge costs in terms of social, economic, and psychological well-being. In the current study, we aimed at investigating how the period of home confinement affected self-reported sleep characteristics in Italians and Belgians, with special regard to sleep timing and subjective quality. Using an online survey we collected data $\underline{\text { from }} 2272$ participants, 1622 Italians (Mage=34.1 13.6 years, $1171 \mathrm{~F}$ ), and 650 Belgian (Mage=43.0 \pm 16.8 years, 509 F). Participants reported their sleep pattern (e.g., bedtime, risetime) and perceived sleep quality during and, retrospectively, before the lockdown. During the lockdown, sleep timing was significantly delayed, time spent in bed increased, and sleep quality was markedly impaired in both Italians and Belgians. The most vulnerable individuals appeared to be women, subjects experiencing a more negative mood, and those perceiving the pandemic situation as highly stressful. However, the two samples differed in the subgroups most affected by the changes, possibly because of the different welfare systems of the two countries. In fact, in the Italian sample sleep quality and timing underwent significant modifications especially in unemployed participants, whereas in the Belgian sample this category was the one who suffered less from the restrictions. Considering that the novel coronavirus has spread across the whole globe, involving countries with different types of health and welfare systems, understanding which policy measures have the most effective protecting role on physical and mental health is of primary importance.
\end{abstract}

Keywords: circadian rhythms; COVID-19; home confinement; sleep; working status 


\section{Introduction}

Italy has been the first western country to face the Coronavirus disease 2019 (COVID-19) emergency and, starting from February 2020, the epidemic spread quickly through Europe. In It-

aly, more than 8,000 people had officially contracted the disease by March $9^{\text {th }} 2020$ (Istituto Superiore di Sanità, 2020), so that on this date the Italian Government imposed a total lockdown over the entire national territory (effective from March $10^{\text {th }}$ until May $3^{\text {rd }}$ ). A similar scenario occurred in Belgium, with a total lockdown imposed by the Government on March $18^{\text {th }} 2020$, and effective until May $4^{\text {th }}$.

During the lockdown, most activities were provisionally closed, including schools, universities, the majority of firms and industries, and non-essential stores. People could leave their homes only when strictly necessary (e.g., to buy food and medicines or to seek medical help). Education (both for school and university grades) was carried out through the Internet, as well as most working activities (i.e., through home working). Indeed, only a limited number of workers were allowed to reach their usual workplace, while many had to interrupt or even lost their jobs. Families had to look after their children at home round the clock and dear ones living in different houses were separated for weeks.

These limitations have proven effective in slowing down the spread of the infection (its curve started sloping down by the end of March 2020 in Italy and a few weeks later in Belgium) and reducing the number of casualties due to the COVID-19, so that a shift to less restrictive measures was eventually made possible in May 2020. However, the benefits obtained in public health have come with huge costs in terms of social, economic, and psychological well-being. 
It has already been reported that prolonged home confinement affected people's physical and mental health (Mazza et al., 2020; Vindegaard \& Benros, 2020; World Health Organization, 2020). Besides the fear of contagion, the uncertainty of the situation, and the lack of face-to-face social interactions, home confinement is associated with reduced exposure to daylight, limited physical activity, and disruption of daily routines (Altena et al., 2020; Brooks et al., 2020; Voitsidis et al., 2020). These changes had a dramatic impact on psychological well-being and sleep/wake patterns (Vindegaard \& Benros, 2020). Early studies on the effect of COVID-19 restrictions on sleep have shown the presence of relevant sleep problems across the world (Casagrande et al., 2020; Cellini et al., 2020; Franceschini et al., 2020; Huang \& Zhao, 2020; Innocenti et al., 2020; Kokou-Kpolou et al., 2020; Mandelkorn et al., 2020; Marelli et al., 2020; Salfi et al., 2020; Stanton et al., 2020; Voitsidis et al., 2020; Xiao et al., 2020). However, only a few studies, with rather small-sized samples, reported comparisons of sleep quality and habits during the lockdown with those before the lockdown. A US-based study on 145 students during the quarantine showed a delay in sleep timing (i.e., midsleep) of about 50 min during weekdays and about 25 min on weekends (Wright et al., 2020). Another study on 435 participants from Switzerland, Germany, and Austria showed that during the lockdown perceived sleep quality (assessed through a single question) was significantly reduced (Blume et al., 2020). An Italian study showed a sleep quality worsening, increased insomnia symptoms, a delayed bed- and risetime on 400 participants, in particular in students and females (Marelli et al., 2020). Finally, two previous studies from our group (conducted on younger samples than that of the present study), showed delayed sleep timing and lower sleep quality compared to the period preceding the lockdown (Cellini et al., 2020; Di Giorgio et al., 2020). In sum, the available studies indicate that 
during the lockdown, 1) sleep quality was markedly compromised, and 2) sleep timing was delayed.

Here, we aimed to more deeply investigate how the COVID-19-related restrictions affected people's self-reported sleep timing and sleep characteristics by addressing these variables in a larger and more heterogeneous population. We investigated the possible changes of these variables during the lockdown not only in a larger Italian sample, with a wider age range and different geographical distribution, but also in the Belgian population, experiencing the same dramatic kind of social confinement but in a country with a different culture, latitude, and baseline sleep-wake habits. In doing so, we also intend to better characterize these changes by taking into account several demographic variables, including age, gender, and working condition during the lockdown.

\section{Methods}

\section{Study design and procedure}

In both countries, participants completed an anonymous, online survey, from April $1^{\text {st }}$ to May $19^{\text {th }}, 2020$. The survey was advertised across the whole nation via social media and University websites. To take part in the survey, participants were asked to read the aims of the study and to explicitly agree to participate in the survey by filling the written consent form. After a few sociodemographic questions (e.g., age, gender, employment status), and some ad-hoc questions related to the COVID-19, a set of standardized questionnaires were presented to the participants, including the Pittsburgh Sleep Quality Index (Buysse et al., 1989). Participants had to respond referring to their current situation (i.e., after March $11^{\text {th }}$ for Italy and March $20^{\text {th }}$ for Belgium) and, retrospectively, to their situation before the lockdown (i.e., until March $10^{\text {th }}$ for Italy and 
March $19^{\text {th }}$ for Belgium). The survey took approximately 25 min to be completed. There was no money or credit compensation for participating in the study. The study protocol was approved by the local ethical committees and was conducted in accordance with the Declaration of Helsinki.

A total of 2272 participants completed the survey (1622 from the Italian and 650 from the Belgian territory). Data reported here were part of a wider research project designed to assess several aspects of sleep characteristics during the quarantine, and other data with different research purposes will be presented elsewhere.

\section{COVID-19 questions}

Several ad-hoc questions related to the COVID-19 emergency were presented. These included, for instance, whether the participants had individuals infected by the COVID-19 among their acquaintances, whether they were worried about their job or education, about the health of their dear ones or about being infected, etc. (0-1 response). We also asked participants whether their working condition had changed during the lockdown (i.e., working from home/remote working, stopped working), how stressed and afraid they felt (on a 3-point scale, i.e. not at all, moderately, extremely,), and how their mood was (on a 5-point scale from extremely positive to extremely negative).

\section{Sleep timing and quality}

Sleep timing and quality were assessed using the PSQI (Buysse et al., 1989). The scoring ranges from 0 to 21, with higher scores indicating worse sleep quality and 5 as a cut-off score to differentiate good from poor sleep (Buysse et al., 1989). From the PSQI questions, we also derived information about bedtime (hh:mm) and risetime (hh:mm), hours spent in bed (hrs), sleep 
duration (hrs), sleep onset latency ( $\mathrm{min}$ ), sleep midpoint (hh:mm), and use of medication for sleeping (either prescribed or over the counter). Each of the questions required two answers: one referring to the current situation and one to the participant's situation before the lockdown.

\section{Statistical analysis}

To assess the changes of sleep parameters across different periods (before and during the lockdown), we employed linear mixed models (LMM), which take into account factors whose levels are randomly extracted from a population (i.e., participants), allowing for more generalizable results (Baayen et al., 2008). We built separate models for sleep quality, sleep timing (bedtime and risetime), time in bed, sleep duration, and sleep onset latency, using Participant as crossed random effects and Lockdown (Before/During Lockdown), Gender (Female/Male), and Work condition (Student, Unemployed/Retired, Stopped working, Remote working, Regular working) as fixed effects, and Age as a covariate. For the Belgian sample, only one participant stopped working during the lockdown and was included in the "Unemployed/Retired" category. Therefore, for the Belgian analysis Work condition was composed of 4 categories (Students, Unemployed/Retired, Remote working, Regular working).

The Holm test was used for post-hoc comparisons. Logistic regressions were conducted to assess the effect of demographic variables (age, gender), presence of sleep issues before the lockdown, use of sleeping pills before the lockdown, and mood, stress, fear of the situation, and fear of being infected (or a relative being infected) in predicting the risk of poor sleep. For each significant predictor, we reported the Odds ratio $(\mathrm{OR})$ and its $95 \%$ confidence interval. A $p<.05$ 
was considered statistically significant. All analyses were run in JASP 0.12.2 (JASP Team, 2020) and JAMOVI 1.2 (The Jamovi Project, 2020).

\section{Results}

\section{Descriptive Statistics}

\section{Italian sample}

Out of the 1622 participants (Mage= $34.1 \pm 13.6$ years, 1171 F), 909 were workers $($ Mage $=41.4 \pm 12.3$ years, 608 F), 591 were university students $($ Mage $=22.5 \pm 3.30$ years, $473 \mathrm{~F})$, and 122 were unemployed or retired (Mage=35.7 \pm 14.09 years, $90 \mathrm{~F})$. Among the workers, during the lockdown, $22.3 \%(203,130 \mathrm{~F})$ continued working at their regular workplace, $49.2 \%$ (447, 296 F) started to work in smart modality, and $28.5 \%(259,182 \mathrm{~F})$ had to stop working. The majority of the sample $(60.2 \%, n=974)$ was from Southern Italy, 28.6\% ( $n=463)$ from Central Italy, $11.1 \%(\mathrm{n}=180)$ from Northern Italy.

As for psychological factors, $37.5 \%$ of the sample reported negative mood, $29.8 \%$ reported a neutral mood, whereas the remaining $35.6 \%$ reported a positive mood during the quarantine. Most participants (68.2\%) reported to be moderately afraid of the COVID-19 emergency, $11.1 \%$ to be extremely afraid, and $20.7 \%$ to be not at all afraid. Regarding the risk of infection (for oneself or dear ones), $56.3 \%$ of the sample reported to be moderately afraid, $36.1 \%$ to be extremely afraid, and only $7.6 \%$ to be not at all afraid. Similarly, $67.3 \%$ of participants reported to be moderately stressed by the COVID-19 situation, $14.2 \%$ to be extremely stressed, and $18.5 \%$ not to be stressed at all.

Most participants were worried about dear ones (95.6\%), economic issues (89\%), risk of infection (81.5\%), and about working (68.2\% of the workers) and academic conditions (92.5\% of the students). Also, 37.5\% ( $\mathrm{n}=608)$ of the sample was acquainted with someone who had been infected by the coronavirus. 


\section{Belgian sample}

Of the 650 participants $($ Mage $=43.0 \pm 16.8$ years, 509 F), 417 were workers (Mage=40.7 \pm 12.2 years, $344 \mathrm{~F}), 89$ were university students $($ Mage=23.7 \pm 6.4 years, $79 \mathrm{~F})$, and 144 were unemployed or retired $($ Mage $=61.8 \pm 14.8$ years, $86 \mathrm{~F})$. Among the workers, during the lockdown, $54.7 \%(228,190 \mathrm{~F})$ continued working as usual whereas $45.3 \%(189,154 \mathrm{~F})$ started to work in smart modality.

During the quarantine, negative mood was reported by $22.3 \%$ of the sample, neutral mood by $27.2 \%$, whereas the remaining $50.5 \%$ reported a positive mood. As for general fear about the health emergency, $37 \%$ of participants were moderately afraid, $15.7 \%$ were extremely afraid, whereas $47.3 \%$ reported being not at all afraid. Moreover, $35.2 \%$ of the sample reported to be moderately afraid of being infected or that dear ones could be infected, $41.2 \%$ to be extremely afraid, and $23.6 \%$ to be not at all afraid. Moderate stress related to the COVID-19 situation was reported by $32.3 \%$ of the sample, extreme stress by $33.7 \%$, whereas $34.0 \%$ did not feel stressed at all.

Two-thirds of the sample were worried about dear ones (67.7\%), less than half about economic issues $(44.4 \%)$, and about being infected (37.2\%). Only $24.5 \%$ of the workers were worried about their work situation $(68.2 \%$ of the workers) whereas $86.5 \%$ of the students were worried about their academic situation. Finally, $14.5 \%(n=94)$ of the sample knew someone who had been infected by the COVID-19.

\section{Effects of the lockdown on sleep}

\section{Italian sample}


Sleep timing markedly shifted during the lockdown. Subjects tended to go to bed later $\left(\mathrm{F}_{1,1612}=286.91, p<.001\right)$, and this effect was mediated by the working status $\left(\mathrm{F}_{4,1611}=5.40\right.$, $p<.001$, Figure 1a). Specifically, students and smart workers tended to go to bed 54 min later $\left(p^{\prime} s<.001\right)$, and participants who were unemployed/retired and those who had to stop working tended to go to bed $1 \mathrm{hr}$ later $(p$ 's $<.001)$. Interestingly, even individuals who continued working regularly tended to delay their bedtime by $24 \min (p=.004)$. We also observed a significant effect of Gender $\left(\mathrm{F}_{1,1612}=12.54, p<.001\right)$, with males tending, in general, to go to bed later than females, although the Lockdown $\times$ Gender interaction was not significant $\left(\mathrm{F}_{1,1612}=0.20, p=.665\right)$. Age was not a significant covariate $(p=.587)$. The shift in bedtime was mirrored by a delayed risetime during the quarantine $\left(\mathrm{F}_{1,1612}=783.77, p<.001\right)$, and, again, this effect was mediated by the working status $\left(\mathrm{F}_{4,1611}=21.25, p<.001\right.$, Figure $\left.1 \mathrm{~b}\right)$. In particular, students got up $1 \mathrm{hr}$ and 40 min later and individuals who had to stop working tended to get up $1 \mathrm{hr}$ and 50 min later than before the lockdown. Unemployed/retired and smart workers got up $1 \mathrm{hr}$ and $25 \mathrm{~min}$ and $1 \mathrm{hr}$ and 14 min later, respectively, whereas individuals who continued working regularly got up 44 min later (all $p$ ' $<.001)$. Again, we observed a significant effect of Gender $\left(\mathrm{F}_{1,1611}=5.39, p=.020\right)$, with females getting up 10 min earlier than males, although the Lockdown $\times$ Gender interaction was not significant $\left(\mathrm{F}_{1,1612}=2.35, p=.125\right)$. Age turned out to be a significant covariate $($ coeff $=$ $0.04, t=-12.33, p<.001)$, with younger subjects getting up later.

These changes in bed- and risetimes are reflected in the observed shift in sleep midpoint during the quarantine $\left(\mathrm{F}_{1,1612}=788.18, p<.001\right)$, which was found to be affected, again, by working status $\left(\mathrm{F}_{4,1611}=14.48, p<.001\right)$. Specifically, sleep midpoint was delayed of $1 \mathrm{hr}$ and $18 \mathrm{~min}$ in students and in unemployed/retired participants, $1 \mathrm{hr}$ and $24 \mathrm{~min}$ in subjects who stopped working, and $1 \mathrm{hr}$ in smart workers (all $p^{\prime} s^{<.001)}$ ). Though less pronounced, a delay was also ob- 
served in regular workers ( $36 \mathrm{~min}, p<.001)$. We observed a significant effect of Gender $\left(\mathrm{F}_{1,1611}=10.24, p=.001\right)$, with males' sleep midpoint occurring 18 min later than that of females, although the Lockdown $\times$ Gender interaction was not significant $\left(\mathrm{F}_{1,1612}=0.05, p=.819\right)$. Age was again a significant covariate $($ coeff. $=-0.02, t=-6.36, p<.001)$, with younger participants showing later sleep midpoints during the quarantine.

\section{Figure 1}

The shift in sleep timing (delayed bedtimes and risetimes) observed during the lockdown was accompanied by an increased duration of time spent in bed (33 min; $\left.\mathrm{F}_{1,1612}=119.85, p<.001\right)$, with differences depending on working condition (Lockdown $\times$ Work: $\mathrm{F}_{4,1612}=4.54, p=.001$, Figure 1c) and gender (Lockdown $\times$ Gender: $\mathrm{F}_{1,1612}=4.91, p=.027$ ). Compared to the period before the restrictions, regular workers spent in bed only 19 min more $(p=.095)$, unemployed/retired subjects $\sim 24$ min more $(p=.056$ ), whereas students, smart workers, and participants who had stopped working significantly increased the time spent in bed up to 46 min (all $p$ 's<.001). Before the lockdown males tended to spend less time in bed than females $(p=.037)$, whereas during the lockdown this difference disappeared $(p=.934)$. Age was a significant covariate $($ coeff. $=-0.04$, $t=-12.09, p<.001)$ : the younger the age, the longer the time spent in bed.

Sleep duration showed a trend to increase of 5 min during the lockdown $\left(F_{1,1612}=3.03\right.$, $p=.082)$. There was a significant main effect of Gender $\left(\mathrm{F}_{1,1611}=8.03, p=.005\right)$, with females sleeping overall 11 min more than males, and a significant Lockdown $\times$ Gender interaction $\left(\mathrm{F}_{1,1612}=14.76, p<.001\right)$, with females sleeping 6 min more during the lockdown whereas males 
slept 16 min more. Age was again a significant covariate $($ coeff. $=-0.03, t=-9.94, p<.001)$ : the younger the age, the longest the time spent asleep during the quarantine.

Sleep latency also showed a significant increase during the period of home confinement $\left(\sim 14.5 \mathrm{~min} ; \mathrm{F}_{1,1612}=189.04, p<.001\right)$, again with differences linked to gender (Lockdown $\times$ Gender: $\left.\mathrm{F}_{1,1612}=4.07, p=.002\right)$ and working condition (Lockdown $\times$ Work: $\mathrm{F}_{4,1612}=4.13, p<.001$, Figure 1d). Before the lockdown, sleep latency did not differ between genders $(p=.998)$. During the lockdown, instead, while females took on average 17.5 min more than before to fall asleep, for males the difference was $11 \mathrm{~min}$ (all $p$ 's $\leq .001)$. The increase in sleep latency in the various working status subgroups ranged from $8.4 \mathrm{~min}$ in the regular workers to $20.4 \mathrm{~min}$ in those who had to stop working (all $p$ 's $<.001)$. Age was a significant covariate $($ coeff $=-0.24, t=-3.83$, $p<.001$ ), with younger subjects taking longer to fall asleep.

Sleep quality (indexed by the PSQI total score) significantly decreased during lockdown $\left(\mathrm{F}_{1,1612}=101.51, p<.001\right)$, especially in female participants (Lockdown $\times$ Gender: $\mathrm{F}_{1,1612}=19.31$, $p<.001$; see Figure 2a). We also observed a significant effect of the working condition $\left(\mathrm{F}_{1,1612}=2.96, p=.019\right)$, with unemployed/retired subjects reporting the worst sleep quality, although the interaction Lockdown $\times$ Work interaction was not significant $\left(\mathrm{F}_{4,1612}=1.40, p=.232\right)$. Age was not a significant covariate $(p=.232)$. The proportion of poor sleepers (i.e., PSQI $>5)$ increased with the lockdown from $37.7 \%$ to $54.2 \%\left(\chi_{1}^{2}=113, p<.001\right)$, with a greater increase in females (from $39.11 \%$ to $58.07 \%$ ) than males (from $34.15 \%$ to $44.12 \%$, Figure 2 b).

Figure 2 
Lastly, the proportion of responders who used medicine to help sleep, as assessed by the PSQI, decreases from $12.3 \%$ to $10.3 \%$.

Logistic regressions $\underline{(\chi 2} \underline{(15)}_{2} \equiv 378, p<.001$. McFadden's $\left.\mathrm{R}^{2}=.169\right)$ confirmed that the risk of poor sleep during the quarantine was higher for subjects already displaying poor sleep before the lockdown $(\mathrm{OR}=2.72 ; 95 \% \mathrm{CI}=2.13-3.47, p<.001)$, in those who were taking sleeping pills before the lockdown $(\mathrm{OR}=1.86 ; 95 \% \mathrm{CI}=1.26-2.73, p=.002)$, for women $(\mathrm{OR}=1.39 ; 95 \% \mathrm{CI}=$ $1.08-1.79, p=.011)$, individuals aged 18-29 yrs $(\mathrm{OR}=1.839 ; 95 \% \mathrm{CI}=1.41-2.25, p<.001$, reference: subjects aged 30-49 yrs), subjects who were extremely scared about the COVID-19 emergency $(\mathrm{OR}=2.07 ; 95 \% \mathrm{CI}=1.23-3.49, p=.006$, reference: no fear), and those who felt moderately $\underline{(\mathrm{OR}=2.08 ; 95 \% \mathrm{CI}=1.52-2.83, p<.001) \text { and extremely stressed }(\mathrm{OR}=4.85 ; 95 \% \mathrm{CI}=2.95-7.97}$ $p<.001$, reference: no stress). Mood was also a significant predictor, with positive mood (reference: neutral mood) showing a protective effect against the risk of experiencing poor sleep quality during the lockdown $(\mathrm{OR}=0.62 ; 95 \% \mathrm{CI}=0.47-0.82, p<.001$, and $\mathrm{OR}=0.6 ; 95 \% \mathrm{CI}=0.25$ $\underline{0.84, p=.012 \text {, for moderate and extreme positive mood, respectively) and negative mood increas- }}$ ing it $(\mathrm{OR}=1.61 ; 95 \% \mathrm{CI}=1.20-2.16, p=.001$, and $\mathrm{OR}=1.90 ; 95 \% \mathrm{CI}=0.90-3.95, p=.091$, for moderate and extreme negative mood, respectively).

\section{Belgian sample}

The substantial changes in sleep timing brought about by the lockdown were also observed in the Belgian sample. Participants delayed their bedtimes $\left(\mathrm{F}_{1,642}=98.03, p<.001\right)$, an effect which was partially mediated by working status $\left(F_{3,642}=2.37, p=.070\right.$, Figure $\left.3 a\right)$, with students going to bed 54 min later, smart workers $\sim 30$ min later, unemployed/retired subjects and regular workers 24 min later (all $p$ 's<.001). A significant effect of Gender was observed $\left(\mathrm{F}_{1,641}=5.01, p=.026\right)$, with males reporting, in general, later bedtimes than females, although no 
Lockdown $\times$ Gender interaction emerged $\left(\mathrm{F}_{1,642}=0.26, p=.609\right)$. Age was a significant covariate (coeff. $=-0.01, t=-3.62, p<.001$ ), with younger subjects going to bed later. As in the Italian sample, during the lockdown risetime was also delayed $\left(\mathrm{F}_{1,642}=268.62, p<.001\right)$, and again this effect was mediated by the working condition $\left(\mathrm{F}_{3,642}=12.69, p<.001\right.$, Figure $\left.3 b\right)$. Specifically, students got up $1 \mathrm{hr}$ and $53 \mathrm{~min}$ later, regular workers $1 \mathrm{hr}$ and 2 min later, smart workers 56 min later, and unemployed/retired subjects $\sim 34$ min later (all $p$ 's<.001). We did not observe a significant effect of Gender $\left(\mathrm{F}_{1,642}=2.00, p=.157\right)$ but Age was again a significant covariate $($ coeff. $=-0.02$, $t=-6.75, p<.001)$ with younger participants getting up later.

\section{Figure 3}

As expected, a significant delay of sleep midpoint during the quarantine was also found $\left(\mathrm{F}_{1,642}=242.92, p<.001\right)$, with differences linked to the working status (Lockdown $\times$ Work: $\left.\mathrm{F}_{3,641}=8.88, p<.001\right)$ : the delay was of $1 \mathrm{hr}$ and $24 \mathrm{~min}$ in students, $48 \mathrm{~min}$ in regular and smart workers, $30 \mathrm{~min}$ in the unemployed/retired (all $p$ 's<.001). Age was again a significant covariate (coeff. $=-0.02, t=-6.03, p<.001)$ : the younger the age, the later the sleep midpoint during the quarantine.

Time spent in bed during the quarantine increased in the Belgian sample by $32 \mathrm{~min}$ $\left(\mathrm{F}_{1,642}=67.23, p<.001\right)$, with differences depending on the working condition (Lockdown $\times$ Work: $\mathrm{F}_{3,642}=6.72, p<.001$, Figure 3c) and gender (Lockdown $\times$ Gender: $\mathrm{F}_{1,642}=3.85, p=.050$ ). Compared to before the lockdown, unemployed/retired participants spent in bed only 9 min more ( $p>.99)$, smart workers $\sim 24$ min more $(p=.004)$, regular workers 36 min more $(p<.001)$, whereas 
students increased their time in bed up to $59 \min (p<.001)$. Before the lockdown males tended to spend less time in bed than females $(p=.064)$ and this difference increased during the confinement $(p<.001)$. Age was a significant covariate (coeff. $=-0.01, t=-2.54, p=.011)$, with younger subjects spending more time in bed.

Sleep duration increased by 19 min during the lockdown $\left(\mathrm{F}_{1,642}=20.87, p<.001\right)$. While there was a significant main effect of Gender $\left(\mathrm{F}_{1,641}=5.27, p=.022\right)$, with females sleeping 17 min more than males, the Lockdown $\times$ Gender interaction was not significant $\left(\mathrm{F}_{1,641}=1.37\right.$, $p=.242)$. Although the Lockdown $\times$ Work interaction was not significant $\left(\mathrm{F}_{3,642}=2.30, p=.076\right)$, we observed an increased sleep duration in regular workers (23 $\mathrm{min} ; p=.011)$. Age was again a significant covariate $($ coeff. $=-0.01, t=-3.08, p=.002)$ with younger participants spending more time asleep during the quarantine.

Sleep latency also increased by $6.5 \min \left(\mathrm{F}_{1,642}=23.24, p<.001\right)$ during the lockdown, an effect which was partially mediated by the working condition (Lockdown $\times$ Work: $F_{3,642}=2.25$, $p=.081$, Figure 3d). It appeared significantly increased in regular workers (6.3 $\mathrm{min}, p=.044)$ and students (12.6 min, $p=.032$ ), but not in the other working status categories (all $p$ 's $>.99$ ). Age was again a significant covariate (coeff. $=-0.17, t=-2.66, p=.008$ ), with longer sleep latencies in younger individuals.

Similarly to Italians, Belgians also displayed decreased sleep quality (indexed by the

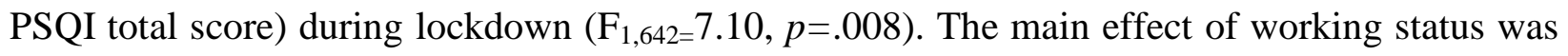

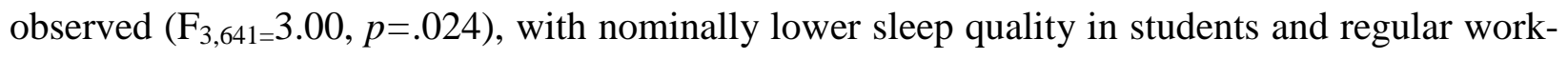
ers compared to unemployed/retired subjects (both $p$ 's=.063), though the interaction Lockdown $\times$ Work was not significant $\left(F_{3,642}=0.40, p=.752\right)$. Gender was not a significant main effect $\left(\mathrm{F}_{1,641}=1.82, p=.178\right)$ and Age was not a significant covariate $\left(\mathrm{F}_{1,641}=1.92, p=.166\right)$. The propor- 
tion of poor sleepers (i.e., PSQI>5) increased from $49.08 \%$ to $53.7 \%$ during the quarantine $\left(\chi_{1}^{2}=103.7, p<.001\right)$ but this change appeared mainly driven by the female participants. In fact, while male poor sleepers decreased from $46.10 \%$ to $39.72 \%$, female poor sleepers increased from $49.90 \%$ to $57.56 \%$ (Figure $4 b$ ).

\section{Figure 4}

Lastly, the proportion of responders who used medicine to help sleep, as assessed by the PSQI, decreases from $25.4 \%$ to $24.2 \%$.

Logistic regressions $\left(\chi 2_{(15)}=214, \mathrm{p}<.001 . \mathrm{McFadden}\right.$ 's $\left.\mathrm{R}^{2}=.250\right)$ confirmed that the risk of poor sleep during the quarantine was higher for subjects already reporting poor sleep before the lockdown $(\mathrm{OR}=4.11 ; 95 \% \mathrm{CI}=2.74-6.16, p<.001)$, in those who were taking sleeping pills before the lockdown $(\mathrm{OR}=3.01 ; 95 \% \mathrm{CI}=1.81-4.99, p<.001)$, for women $(\mathrm{OR}=1.99 ; 95 \% \mathrm{CI}=$ 1.21-3.28, $p=.007)$, and for participants who felt extremely stressed ( $\mathrm{OR}=2.34 ; 95 \% \mathrm{CI}=1.26-$ 4.35, $p=.007$, reference: no stress). Mood was again a significant predictor, with extremely posi$\underline{\text { tive mood (reference: neutral mood) bearing a protective effect against the risk of poor sleep }}$ quality during the lockdown $(\mathrm{OR}=0.47 ; 95 \% \mathrm{CI}=0.26-0.86, p=.015)$, and extremely negative mood increasing its risk $(\mathrm{OR}=7.79 ; 95 \% \mathrm{CI}=2.14-28.30, p=.002)$.

\section{Discussion}

In the current study, we aimed to investigate how the period of home confinement imposed by governments to contain the spread of the COVID-19 epidemic in two European counties, Italy and Belgium, affected people's self-reported sleep characteristics, with special regard to sleep timing and subjective quality. Of note, to the best of our knowledge, this is the first re- 
port of sleep changes during the lockdown in a Belgian sample. As hypothesized, the two countries showed a similar pattern of changes in the main variables of interest after the introduction of COVID-19-related restrictions: sleep timing was significantly delayed during the lockdown, time spent in bed increased, and sleep quality was markedly impaired in both Italy and Belgium. At the same time, these changes differently affected specific subgroups of participants in the two countries.

First of all, in both Italy and Belgium, participants tended to go to bed later than usual during the lockdown. This delay was more pronounced in students, whose bedtime was delayed of about $54 \mathrm{~min}$ in both countries, and in males compared to females. Similarly, people tended to wake up later in the morning, and again in both countries students were the ones showing the most pronounced delay (1 hr and $40 \mathrm{~min}$ and $1 \mathrm{hr}$ and $52 \mathrm{~min}$ in the Italian and Belgian sample, respectively). Overall, the shift in sleep midpoint was similar in the two countries, i.e., $\sim 1 \mathrm{hr}$ and 1 min and $\sim 54$ min in the Italian and Belgian samples, respectively. Italy and Belgium also showed a similar increase of time spent in bed with the lockdown, i.e. $\sim 33$ min in the Italian sample and $\sim 32 \mathrm{~min}$ in the Belgian sample.

However, the longer time spent in bed was not accompanied by a corresponding increase in sleep duration in either sample, indicating a decrease in sleep efficiency. In line with this, in both countries subjective sleep quality was significantly impaired, with an increased proportion of poor sleepers (especially females) compared to before the quarantine. This worsening of sleep quality was also reflected in an increased perception of difficulties falling asleep, suggested by the significant increase in self-reported sleep latency. Possibly sleep continuity and stability were also impaired, i.e., through increased awakening and arousal frequency (Conte et al., 2020), although we cannot draw firm conclusions from our data. 
Several factors may have played a role in determining the worsening of subjective sleep quality during the period of home confinement. First of all, as suggested by the results of our regressions, showing, in both countries, an increased risk of poor sleep in subjects with higher negative mood and stress, psychological factors related to the COVID-19 crisis have likely had a significant impact on sleep quality and timing (Altena et al., 2020; Alvaro et al., 2013; Coles et al., 2015). Second, the changes in daily routines, including working from home and the lack of social activities, have probably contributed to the sleep quality impairments (Carney et al., 2006; Monk et al., 1994), either directly or indirectly by affecting mood and stress. Also, the changes in daily habits could have included an increase of daytime naps, which might have resulted, for homeostatic reasons, in decreased sleep pressure at bedtime, on its turn responsible for longer sleep latency and greater sleep fragmentation.

Unsurprisingly, our data show that, both in Italy and Belgium, subjects already experiencing poor sleep quality before the lockdown were at higher risk of being classified as poor sleepers during the lockdown as well. Furthermore, consistent with what predicted by the task force of the European CBT-I Academy (Altena et al., 2020), women appeared more vulnerable to remaining or becoming poor sleepers during home confinement in both countries. This is likely due to the higher prevalence of insomnia in this population (Altena et al., 2020), to the "gender gap" in childcare (Craig \& Mullan, 2011) and eldercare (Brenna \& Di Novi, 2016), and to wages gap, although the latter is quite limited in Belgium (Boll \& Lagemann, 2018).

Overall, our data are in line with previous studies on the impact of the pandemic-related restrictive measures on sleep quality in Italy (Casagrande et al., 2020; Cellini et al., 2020; Franceschini et al., 2020; Marelli et al., 2020; Salfi et al., 2020) and other European countries (Kokou-Kpolou et al., 2020; Stanton et al., 2020; Voitsidis et al., 2020), as well as in Chinese 
(Huang \& Zhao, 2020; Xiao et al., 2020), Australian (Stanton et al., 2020), and US samples (Wright et al., 2020), suggesting that the negative effect of confinement on perceived sleep quality was not specific of a single region, but can be generalized to most of the industrialized countries. Moreover, our data confirm, and extend to Belgium, the marked shift in sleep timing observed during the lockdown in countries with a very different culture, latitude, and longitude such as Italy (Cellini et al., 2020), Austria, Germany and Switzerland (Blume et al., 2020), and the US (Wright et al., 2020).

Despite the striking similarities in the lockdown-related sleep changes affecting the two samples as a whole, the two countries differed in the most affected subgroups. In fact, in the Italian sample sleep quality and timing underwent significant modifications especially in unemployed participants, whereas in the Belgian sample this category was the one who suffered less from the restrictions. This difference may be due to the different welfare of the two countries, and to the general income of the population. In the last decades, Belgium has placed a robust and redistributive welfare system (despite its complexity), centered on minimum income protection as well as on social risk such as long term unemployment financial aids (Marx \& Schuerman, 2016). Belgian unemployed individuals have a relatively good protection level, characterized by long-lasting income benefits and unemployment insurance with an initial replacement rate of $60 \%$ with no time limit (Mariña et al., 2012). In Italy, instead, although the welfare system is also quite complex and specific economic measures have been implemented during the lockdown (Figari \& Fiorio, 2020), it has been estimated that losses for the lower socioeconomic classes and wage inequality increased during this period more than in Belgium. Although it is unlikely that the general population was aware of these estimations, people in both countries likely had a different perception of health- and economic-related risks. Indeed, Italian participants, compared to 
the Belgian, reported more frequently a negative mood, more fear about the COVID-19 situation, and a higher proportion of the sample reported to be worried about dear ones and economic issues.

Our results should be considered in light of methodological constraints linked to the na$\underline{\text { ture of survey studies: for instance, we cannot exclude that responses were biased by recall accu- }}$ racy of respondents or that the questionnaire might have preferentially attracted responders with pre-existing sleep complaints (Jones et al., 2013). Nevertheless, has been recently demonstrated that data elicited by retrospective questions are quite consistent (Hipp et al., 2020). Moreover, this methodology allowed for the major asset of this study, which is the collection of the same data from quite large samples in two different countries. Our findings clearly showed that the changes in sleep timing and quality described during the lockdown in several countries are related to the restrictions imposed by governments to face the COVID-19 crisis. Indeed, in both Italy and Belgium, we observed longer time spent in bed, delay in sleep timing, and worsening sleep quality.

Furthermore, in our investigation we have adopted a special focus on factors affecting the risk of developing or worsening sleep complaints as adverse consequences of pandemic-related restrictions, highlighting a particular vulnerability for women, subjects experiencing a more negative mood, and those perceiving the situation as highly stressful. This kind of analysis, which sheds only a partial light on a complex scenario, opens the way to further studies addressing other possible modulating variables (both risk and protective factors, e.g., the use of pharmacological and/or behavioral treatments for sleep quality, the presence of different pre-existing psychopathologies or personality traits, the influence of chronotype or of different social roles such as 
being a health care professional, etc.), to build an increasingly clearer picture of the complex effects of global health emergencies on sleep health.

In particular, in the current study, we were not able to investigate the sleep-wake pattern in specific workers, such as healthcare professionals. This working category is at high risk for poor sleep and insomnia (Chokroverty, 2020; Ferini-Strambi et al., 2020). As shown by FeriniStrambi and colleagues (2020), about $35 \%$ of Italian healthcare staff (e.g., physicians, nurses) reported sleep disturbances at the subjective (i.e., PSQI) and objective (i.e., actigraphy) level. The reduced sleep quality in this population is alarming since it can increase the susceptibility of medical staff to COVID-19 infection, therefore increase the probability of infection outbreak, and can negatively affect mental health in a population already under high stress (Maunder et al., 2006).

Another point, not addressed in the current study, is the characterization of sleep during quarantine in individuals suffering from psychiatric disorders (e.g., anxiety, depression, psycho$\underline{\text { sis). Indeed, considering that there is a tight relationship between sleep and psychiatric disorders }}$ (Freeman et al., 2020), investigating the change in sleep pattern during a quarantine may be of primary importance to improve mental healthcare.

Another important point, not addressed in the current study, is how sleep quality changed across the confinement period. Indeed, as shown by Salfi and colleagues (Salfi et al., 2020), sleep quality seems to remain low across the lockdown, although males tend to show a reduction of sleep quality over time. In the current study we could not replicate the same analysis since $\underline{88.1 \% \text { of the Italian sample }(\mathrm{N}=1429) \text { completed the survey in the first week of data collection }}$ $\left(31^{\text {st }}\right.$ of March $-6^{\text {th }}$ of April), while only $11.9 \%$ of the data $(N=193)$ have been collected in the period between the $7^{\text {th }}$ to the $21^{\text {st }}$ of April. Similarly, in the Belgian sample, we collected $74.6 \%$ 
of the data $(\mathrm{N}=485)$ in the first week of data collection $\left(8^{\text {th }}-14^{\text {th }}\right.$ of April $)$, while only $25.4 \%$ of the data $(\mathrm{N}=165)$ have been collected in the period between the $15^{\text {th }}$ of April to the $19^{\text {th }}$ of May. Therefore, a direct comparison of our data between these two periods could not be done due to the large differences in sample size. Nevertheless, our sleep quality and timing data are con$\underline{\text { sistent with the findings of our previous study in young adults (Cellini et al., 2020), where data }}$ were collected during the third week of the Italian lockdown $\left(24^{\text {th }}\right.$ to $28^{\text {th }}$ of March $)$.

Overall, the differences we observed in the current study between countries in the subgroups most vulnerable to sleep quality impairments point to the importance of welfare systems in impacting risk perception, possibly through the development of different narratives of the COVID-19 emergency in the two countries (Olagoke et al., 2020). Specifically, the protective role of a well-functioning welfare system requires further attention. Considering that the novel coronavirus has spread across the whole globe, involving countries with different types of health and welfare systems, understanding which policy measures have the most effective protective role on physical and mental health is of primary importance. Moreover, in light of the new increases in the spread of contagion, politicians, clinicians, and researchers should be ready to propose adequate interventions to reduce the physical and psychological burden of this unprecedented situation, especially for the most vulnerable individuals. 


\section{References}

Altena, E., Baglioni, C., Espie, C. A., Ellis, J., Gavriloff, D., Holzinger, B., Schlarb, A., Frase, L., Jernelöv, S., \& Riemann, D. (2020). Dealing with sleep problems during home confinement due to the COVID- 19 outbreak: practical recommendations from a task force of the European CBT- I Academy. Journal of Sleep Research, 29(4), e13052.

Alvaro, P. K., Roberts, R. M., \& Harris, J. K. (2013). A systematic review assessing bidirectionality between sleep disturbances, anxiety, and depression. Sleep, 36(7), 10591068.

Baayen, R. H., Davidson, D. J., \& Bates, D. M. (2008). Mixed-effects modeling with crossed random effects for subjects and items. Journal of Memory and Language, 59(4), 390-412.

Blume, C., Schmidt, M. H., \& Cajochen, C. (2020). Effects of the COVID-19 lockdown on human sleep and rest-activity rhythms. Current Biology, 30(14), 795-R797.

Boll, C., \& Lagemann, A. (2018). Gender pay gap in EU countries based on SES (2014). Luxembourg, Publication Office of the European Union. doi, 10, 978935.

Brenna, E., \& Di Novi, C. (2016). Is caring for older parents detrimental to women's mental health? The role of the European North-South gradient. Review of Economics of the Household, 14(4), 745-778.

Brooks, S. K., Webster, R. K., Smith, L. E., Woodland, L., Wessely, S., Greenberg, N., \& Rubin, G. J. (2020). The psychological impact of quarantine and how to reduce it: rapid review of the evidence. The Lancet, 395(10227), 912-920.

Buysse, D. J., Reynolds III, C. F., Monk, T. H., Berman, S. R., \& Kupfer, D. J. (1989). The Pittsburgh Sleep Quality Index: a new instrument for psychiatric practice and research. Psychiatry Research, 28(2), 193-213. https://doi.org/10.1016/0165-1781(89)90047-4

Carney, C. E., Edinger, J. D., Meyer, B., Lindman, L., \& Istre, T. (2006). Daily activities and sleep quality in college students. Chronobiology International, 23(3), 623-637.

Casagrande, M., Favieri, F., Tambelli, R., \& Forte, G. (2020). The enemy who sealed the world: Effects quarantine due to the COVID-19 on sleep quality, anxiety, and psychological distress in the Italian population. Sleep Medicine.

Cellini, N., Canale, N., Mioni, G., \& Costa, S. (2020). Changes in sleep pattern, sense of time and digital media use during COVID- 19 lockdown in Italy. Journal of Sleep Research, 29(4), e13074.

Chokroverty, S. (2020). The Many Faces and Fangs of COVID-19: An Editorial. Sleep Medicine.

Coles, M. E., Schubert, J. R., \& Nota, J. A. (2015). Sleep, circadian rhythms, and anxious traits. Current Psychiatry Reports, 17(9), 73.

Conte, F., Cerasuolo, M., Fusco, G., Giganti, F., Inserra, I., Malloggi, S., Di Iorio, I., \& Ficca, G. (2020). Sleep continuity, stability and organization in good and bad sleepers. Journal of Health Psychology, 1359105320903098.

Craig, L., \& Mullan, K. (2011). How mothers and fathers share childcare: A cross-national timeuse comparison. American Sociological Review, 76(6), 834-861.

Di Giorgio, E., Di Riso, D., Mioni, G., \& Cellini, N. (2020). The interplay between mothers' and children behavioral and psychological factors during COVID-19: An Italian study. European Child and Adolescent Psychiatry.

Ferini-Strambi, L., Zucconi, M., Casoni, F., \& Salsone, M. (2020). COVID-19 and sleep in medical staff: reflections, clinical evidences, and perspectives. Current Treatment Options in Neurology, 22(10), 1-6. 
Figari, F., \& Fiorio, C. V. (2020). Welfare resilience in the immediate aftermath of the covid-19 outbreak in italy. EUROMOD at the Institute for Social and Economic Research, Tech. Rep.

Franceschini, C., Musetti, A., Zenesini, C., Palagini, L., Pelosi, A., Quattropani, M. C., Lenzo, V., Freda, M. F., Lemmo, D., \& Vegni, E. (2020). Poor sleep quality and its consequences on mental health during the COVID-19 lockdown in Italy. Frontiers in Psychology, 11, 3072.

Freeman, D., Sheaves, B., Waite, F., Harvey, A. G., \& Harrison, P. J. (2020). Sleep disturbance and psychiatric disorders. The Lancet Psychiatry, 7(7), 628-637.

Hipp, L., Bünning, M., Munnes, S., \& Sauermann, A. (2020). Problems and pitfalls of retrospective survey questions in COVID-19 studies. Survey Research Methods, 14, 109114.

Huang, Y., \& Zhao, N. (2020). Generalized anxiety disorder, depressive symptoms and sleep quality during COVID-19 outbreak in China: a web-based cross-sectional survey. Psychiatry Research, 112954.

Innocenti, P., Puzella, A., Mogavero, M. P., Bruni, O., \& Ferri, R. (2020). Letter to editor: CoVID-19 pandemic and sleep disorders - a web survey in Italy. Neurological Sciences, 41(8), 2021-2022.

Istituto Superiore di Sanità. (2020, March 9, 2020). Comunicato stampa N¹9/2020. Studio ISS. Un paziente su cinque positivo al coronavirus ha tra 19 e 50 anni. Retrieved March 30, 2020 from https://www.iss.it/comunicati-stampa1

Jones, T., Baxter, M., \& Khanduja, V. (2013). A quick guide to survey research. The Annals of The Royal College of Surgeons of England, 95(1), 5-7.

Kokou-Kpolou, C. K., Megalakaki, O., Laimou, D., \& Kousouri, M. (2020). Insomnia during COVID-19 pandemic and lockdown: Prevalence, severity, and associated risk factors in France population. Psychiatry Research, 113128.

Mandelkorn, U., Genzer, S., Choshen-Hillel, S., Reiter, J., Meira e Cruz, M., Hochner, H., Kheirandish-Gozal, L., Gozal, D., \& Gileles-Hillel, A. (2020). Escalation of sleep disturbances amid the COVID-19 pandemic: a cross-sectional international study. Journal of Clinical Sleep Medicine, jcsm. 8800.

Marelli, S., Castelnuovo, A., Somma, A., Castronovo, V., Mombelli, S., Bottoni, D., Leitner, C., Fossati, A., \& Ferini-Strambi, L. (2020). Impact of COVID-19 lockdown on sleep quality in university students and administration staff. Journal of Neurology, 1-8.

Mariña, F. S., Figari, F., Sutherland, H., \& Tumino, A. (2012). Welfare compensation for unemployment in the Great Recession.

Marx, I., \& Schuerman, N. (2016). Belgium, or how inertia can have unexpected benefits in times of crisis. In Challenges to European welfare systems (pp. 37-57). Springer.

Maunder, R. G., Lancee, W. J., Balderson, K. E., Bennett, J. P., Borgundvaag, B., Evans, S., Fernandes, C. M., Goldbloom, D. S., Gupta, M., \& Hunter, J. J. (2006). Long-term psychological and occupational effects of providing hospital healthcare during SARS outbreak. Emerging Infectious Diseases, 12(12), 1924.

Mazza, C., Ricci, E., Biondi, S., Colasanti, M., Ferracuti, S., Napoli, C., \& Roma, P. (2020). A nationwide survey of psychological distress among italian people during the COVID-19 pandemic: Immediate psychological responses and associated factors. International Journal of Environmental Research and Public Health, 17(9), 3165. 
Monk, T. H., Petrie, S. R., Hayes, A. J., \& Kupfer, D. J. (1994). Regularity of daily life in relation to personality, age, gender, sleep quality and circadian rhythms. Journal of Sleep Research, 3(4), 196-205.

Olagoke, A. A., Olagoke, O. O., \& Hughes, A. M. (2020). Exposure to coronavirus news on mainstream media: The role of risk perceptions and depression. British Journal of Health Psychology, e12427.

Salfi, F., Lauriola, M., Amicucci, G., Corigliano, D., Viselli, L., Tempesta, D., \& Ferrara, M. (2020). Gender-related time course of sleep disturbances and psychological symptoms during the COVID-19 lockdown: A longitudinal study on the Italian population. Neurobiology of stress, 100259.

Stanton, R., To, Q., Khalesi, S., Williams, S., Alley, S., Thwaite, T., Fenning, A., \& Vandelanotte, C. (2020). Depression, Anxiety and Stress during COVID-19: Associations with Changes in Physical Activity, Sleep, Tobacco and Alcohol Use in Australian Adults. International Journal of Environmental Research and Public Health, 17(11), 4065.

Vindegaard, N., \& Benros, M. E. (2020). COVID-19 pandemic and mental health consequences: systematic review of the current evidence. Brain, Behavior and Immunity.

Voitsidis, P., Gliatas, I., Bairachtari, V., Papadopoulou, K., Papageorgiou, G., Parlapani, E., Syngelakis, M., Holeva, V., \& Diakogiannis, I. (2020). Insomnia during the COVID-19 pandemic in a Greek population. Psychiatry Research, 113076.

World Health Organization. (2020). Mental health and psychosocial considerations during the COVID-19 outbreak. (No. WHO/2019-nCoV/MentalHealth/2020.1). Retrieved 27 March 2020 from https://apps.who.int/iris/bitstream/handle/10665/331490/WHO-2019-nCoVMentalHealth-2020.1-eng.pdf?sequence $=1 \&$ isAllowed $=y$

Wright, K. P., Linton, S. K., Withrow, D., Casiraghi, L., Lanza, S. M., de la Iglesia, H., Vetter, C., \& Depner, C. M. (2020). Sleep in University Students Prior to and During COVID-19 Stay-at-Home Orders. Current Biology, 30(14), R797-798.

Xiao, H., Zhang, Y., Kong, D., Li, S., \& Yang, N. (2020). Social capital and sleep quality in individuals who self-isolated for 14 days during the coronavirus disease 2019 (COVID19) outbreak in January 2020 in China. Medical Science Monitor: international medical journal of experimental and clinical research, 26, e923921-923921. 